\title{
Serviço de Orientação Via E-mail: Novas Considerações
}

Ivelise Fortim \&

Leonardo Antonio Marui Cosentino

Pontifícia Universidade Católica de São Paulo
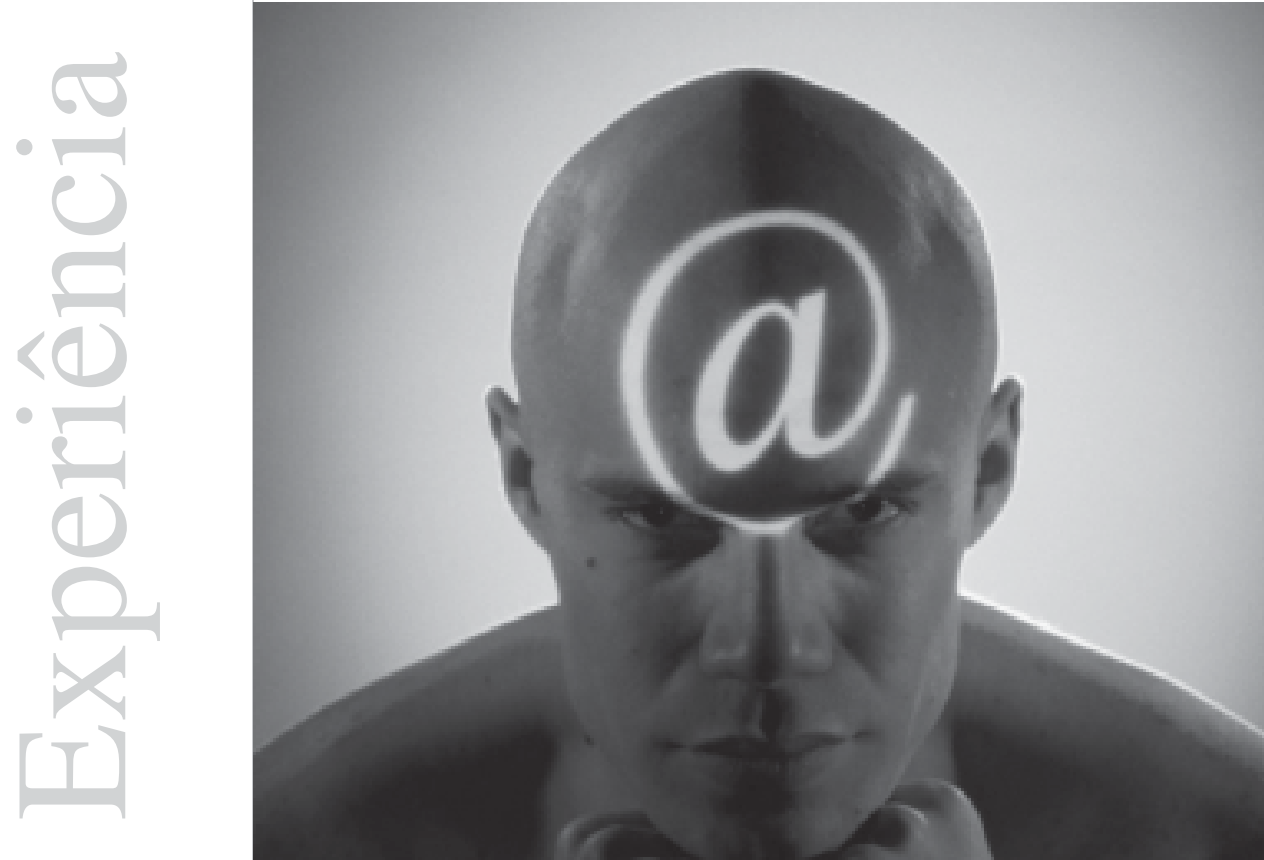

Nossos agradecimentos à equipe do NPPI que colaborou com a pesquisa: Rosa M. Farah, Lorival Novo, Erick Itakura, Guilherme

Ohl, Juliana Zacharias, Katty

Zuñiga, Luciana Ruffo, Maluh Duprat e Paulo Lopes. 
Resumo: Este artigo se propõe a analisar o aumento crescente da demanda do serviço de orientação psicológica via e-mail, desenvolvido pelo Núcleo de Pesquisa de Psicologia e Informática da Clínica Psicológica Ana Maria Poppovic, da Pontifícia Universidade Católica de São Paulo. Partindo de uma breve retrospectiva dos serviços do núcleo, do perfil dos usuários, dos tipos de pedidos e dos temas centrais das mensagens nos anos 2003 e 2004, este texto apresenta novas reflexões sobre uma área de pesquisa muito proeminente dentro da Psicologia, incluindo elementos atuais às hipóteses anteriormente formuladas. As recentes transformações e atualizações tecnológicas pedem constantes análises, que são necessárias à promoção de qualidade e ética no exercício da profissão mediado pelo computador.

Palavras-chave: Psicologia e informática, serviço de orientação psicológica via e-mail, correio eletrônico, computador, virtual.

\begin{abstract}
This article considers the analysis the continuous increase of the counseling service demand by e-mail developed at the Center for Research in Psychology and Informatics. Starting from a brief retrospective of the services, using the users' profile data and the messages' main issues in the years 2003 and 2004, this text presents new considerations about a very prospective research area in Psychology, including current elements to the hypotheses that were previously formulated. The recent transformations and the technological updates require constant analysis about the counseling service, which are necessary to promote quality and ethics in the professional activity mediated by computer.
\end{abstract}

Key words: Psychology and data processing, counseling service by e-mail, electronic mail, computer, virtual.

Este artigo visa a compreender o aumento do número de $e$-mails de orientação recebidos pelo serviço de orientação psicológica do Núcleo de Psquisas de Psicologia e Informática (NPPI), da Clínica Psicológica Ana Maria Poppovic, da Pontifícia Universidade Católica de São Paulo (PUC-SP). O serviço apresenta, desde sua criação, um aumento crescente no número de mensagens recebidas. Foi, então, realizado um levantamento de dados dos $e$ mails de orientação psicológica recebidos nos anos 2003 e 2004, com a finalidade de compreender melhor quem utiliza o serviço, para quem se destina e porque, obtendo-se, assim, uma melhoria dos serviços prestados pelo núcleo, sem perder de vista o objetivo central do presente trabalho.

Com esse intuito, é realizada uma breve retrospectiva sobre o serviço e, em seguida, são apresentados os dados sobre os e-mails de orientação recebidos no período citado e levantadas hipóteses, de acordo com os dados obtidos, sobre os motivos pelos quais as pessoas utilizam esse serviço bem como sobre o aumento do número de mensagens de orientação psicológica.

\section{Breve retrospectiva do serviço de orientação psicológica por $e$-mail do NPPI}

O NPPI da Clínica Psicológica Ana Maria Poppovic, da PUC-SP, foi criado em 1995. Inicialmente, consistia apenas na concepção de uma edição informatizada do Boletim Clínico, publicação criada pelo Prof. Dr. Efraim Boccalandro. A partir dessa publicação, foi construído um projeto maior: uma home page para a Clínica Psicológica, tendo como meta a agilização da comunicação Clínica Comunidade. Em julho de 1997, foi elaborada a primeira versão do site da Clínica da PUCSP. Hoje, após algumas revisões e ampliações, é o meio pelo qual a clínica recebe a maior parte da correspondência eletrônica. 
Posteriormente, o núcleo foi assumindo outros objetivos e desempenhando outras atividades. Atualmente, além da atualização e manutenção da home page e da correspondência eletrônica da Clínica-escola, destaca-se a oferta de campo de estágio aos psicólogos interessados na área de estudo e pesquisa da Psicologia e informática, o desenvolvimento e supervisão de novas modalidades de serviços psicológicos informatizados, como a Orientação Psicológica via e-mail (do qual se trata este artigo) e a orientação profissional via internet, além da oferta de atendimento presencial às pessoas com dificuldades geradas pelos usos excêntricos (ou patológicos) das novas tecnologias. Compõem também o conjunto das atividades do núcleo a oferta de uma cadeira eletiva aos alunos da Faculdade de Psicologia da PUC-SP sobre a interface Psicologia/informática, o serviço de orientação à comunidade, através de palestras e entrevistas à imprensa, a continuidade das pesquisas e reflexões sobre os efeitos gerados pela difusão dos recursos da informática nos diversos campos das atividades e interações humanas e a participação, junto aos órgãos de classe, nas discussões das questões éticas envolvidas nos serviços psicológicos mediados por computador (Farah, 2004a). Entre todas as atividades citadas, a principal desenvolvida pelo núcleo é o serviço de orientação psicológica via e-mail.

No início, a divulgação do link denominado Fale com a Clínica visava apenas a facilitar a comunicação dos trabalhos de ensino e pesquisa realizados na Clínica-escola junto à comunidade acadêmica e à população em geral. Assim, de maneira espontânea, e através da existência da home page, o serviço de orientação psicológica via $e$-mail foi criado e iniciado.

Quando as mensagens que continham algum tipo de pedido de ajuda psicológica começaram a chegar, no final de 1999, foram motivo de surpresa para a equipe. Os primeiros pedidos continham relatos de situações angustiantes e pediam “conselhos”. Cabe destacar que, na época, em nenhum ponto da home page era oferecido qualquer tipo de serviço que envolvesse atendimento ou mesmo orientação psicológica via e-mail. As informações divulgadas referiam-se essencialmente aos atendimentos presenciais realizados na própria clínica.

Assim, foram respondidos os primeiros pedidos utilizando aquela que parecia ser a melhor forma: de maneira geral, era oferecido o encaminhamento que parecia ser o mais viável e/ou acessível ao pedido em pauta, na maioria das vezes, oferecendo ao remetente os recursos disponíveis na clínica. Quando os pedidos vinham de outros Estados ou cidades, a orientação era dada no sentido de que as pessoas procurassem uma ajuda psicológica presencial na Clínica-escola ou instituição assistencial mais próxima do seu local de origem.

No entanto, outras mensagens semelhantes continuavam chegando, o que exigiu uma reflexão maior da equipe. A primeira constatação foi o alto grau de sofrimento psíquico presente na maior parte dos relatos enviados, e por essa razão, o pedido de ajuda via e-mail revelou-se um novo meio pelo qual as pessoas poderiam expressar suas angústias. Seria esse um novo canal de comunicação ao qual o psicólogo deveria dar atenção e disponibilizar uma prática psicológica? Em caso positivo, qual seria a melhor forma de fazê-lo? A proposta do NPPI, portanto, foi a de desenvolver um serviço de orientação psicológica via e-mail, aproveitando, dessa maneira, a correspondência eletrônica como recurso criado e utilizado espontaneamente pela população.

Paralelamente, ainda no final de 1999, a equipe participava da discussão sobre a viabilidade da realização dos atendimentos psicológicos via 
internet, junto ao Conselho Federal de Psicologia (CFP), e, assim, sabia-se que ainda não havia ainda sido estabelecida uma regulamentação que pudesse nortear, do ponto de vista ético, a realização desse tipo de atendimento à população. A busca da melhor forma de oferecer esse serviço foi se constituindo por meio da prática da interação com o visitante, procurando-se sempre compreender "quem" escrevia, e ainda "por que" o fazia dessa forma. Foi esse contato que permitiu identificar "o que" essa pessoa precisaria receber como resposta para que pudesse efetivamente ser ajudada. Assim se iniciou a busca pelas formas mais adequadas de atendimento a essas mensagens, que se tornaram, desde então, objeto de trabalho e pesquisa da equipe.

A partir do ano 2000, pautado pela Resolução CFP n 003/2000, o serviço de orientação psicológica por e-mail foi oficializado. Sua oferta foi inserida na forma de um link dentro da home page, que remete o usuário para as instruções de como usar o serviço bem como para os preceitos éticos que o norteiam.

Atualmente, esse serviço obedece às normas estabelecidas pela Resolução $n^{\circ}$ 012/2005, promulgada pelo Conselho supracitado, em 18 de agosto de 2005, referentes ao atendimento psicológico mediado por computador, em substituição à Resolução anterior, n 003/2000. De acordo com o artigo $6^{\circ}$ dessa Resolução, é reconhecida e autorizada pelo CFP a realização de diversas formas de "orientação psicológica" através de meios eletrônicos, inclusive a internet, desde que sejam observadas as normas éticas detalhadas no texto da própria Resolução e do Código de Ética Profissional da categoria.

\section{Diferenças entre orientação psicológica e psicoterapia on line}

O serviço de orientação psicológica trabalha com limites muito tênues entre o espaço terapêutico e a psicoterapia. Sendo assim, cabem aqui alguns esclarecimentos. Primeiramente, a Resolução CFP n 012/2005 estabelece, como psicoterapia on line, a prática de um tratamento psicoterapêutico mediado pelo computador. Na maioria das vezes, tratase de um modelo de psicoterapia presencial transposto para a internet. Atualmente, essa prática só é permitida pelo Conselho como forma de pesquisa aprovada por comitê de ética filiado ao Conselho Nacional de Saúde. Entretanto, estão autorizados, pelo Conselho, os demais serviços psicológicos previstos na Resolução citada, tais como orientação psicológica e afetivo-sexual, orientação profissional, orientação de aprendizagem e Psicologia escolar, orientação ergonômica, consultorias a empresas, reabilitação cognitiva, ideomotora e comunicativa (Resolução CFP $n^{\circ} 012 / 2005$ ).

Existem diversos tipos de orientação psicológica que podem ser feitas pela internet. A mais comum é via $e$-mail, que visa a orientar sobre um assunto especifico, encerrando o tema na própria mensagem e/ou indicando o atendimento presencial. Existem também as orientações psicológicas via listas de discussão ou fóruns, via sites ou home pages, onde se veiculam textos à maneira de orientações feitas em revistas, orientações em salas de chat e, mais recentemente, orientações via voz e webcameras (Fortim, 2004).

Uma das principais diferenças entre a psicoterapia on line e os demais serviços psicológicos mediados pelo computador é o foco da mensagem interpretada pelo profissional (Fortim, 2004). No serviço de orientação psicológica, a proposta é focar um assunto específico contido na mensagem, buscando compreender a questão central e devolver a orientação pontualmente, ou seja, voltada especificamente para essa questão. Outra peculiaridade fundamental do serviço de orientação é a preocupação de não construir um vínculo duradouro com o usuário. 
Quando se trata de atendimento psicológico, o encaminhamento é feito basicamente para clínicas-escola ou serviços públicos de instituições reconhecidas, presentes no cadastro que a Clínica Psicológica daPUC-SP mantém.
Em outras palavras, o número de e-mails ou de troca de informações deve ser limitado.

No NPPI, o serviço se desenvolve da seguinte forma: são encaminhadas mensagens para nosso endereço eletrônico, que são recebidas por uma equipe de psicólogos, visando, assim, a garantir o sigilo das informações. Os e-mails são lidos pela equipe e supervisionados por um coordenador responsável para essa função, ao modo de uma supervisão de caso clínico. Em seguida, a equipe redige a resposta, que é encaminhada ao remetente.

As respostas podem ser tão variadas como as mensagens, ou seja, podem ser respostas objetivas a perguntas pontuais, tais como informações sobre o desenvolvimento infantil, ou podem ser respostas mais complexas e elaboradas, como relatos de casos onde há grande sofrimento envolvido. Nesse segundo tipo de $e$-mail, por todas as restrições do meio utilizado, as respostas enviadas pelo serviço focam determinado ponto já contido na própria solicitação, e procuram ajudar o remetente a transformar o sofrimento em um impulso para resolvê-lo. A orientação visa a tornar a problemática passível de uma reflexão mais ampla pelo remetente, ou seja, procura lançar luz sobre pontos obscuros e apontar algumas conexões que, eventualmente, se tornaram impossíveis ou pouco claras, pela própria condição vivida por aqueles que procuram o serviço.

Assim, as respostas enviadas podem ter como objetivo possibilitar que o indivíduo reflita sobre a situação, ou, se for um caso mais grave, se sensibilize para procurar ajuda presencial. Nesse sentido, o serviço de orientação contribui para transformar a “queixa” em “demanda”, tornando o espaço virtual, possivelmente, um espaço terapêutico, ou, pelo menos, parte dele.
De acordo com a natureza e gravidade do relato analisado, é prática que se indique, para aquele que busca o serviço de orientação psicológica, a procura por um profissional capacitado a ajudá-lo de uma forma mais consistente e adequada. Quando se trata de atendimento psicológico, o encaminhamento é feito basicamente para clínicas-escola ou serviços públicos de instituições reconhecidas, presentes no cadastro que a Clínica Psicológica da PUC-SP mantém. O mesmo critério é usado para encaminhamentos feitos a profissionais de outras especialidades. É válido destacar que há uma preocupação e cuidados constantes com os encaminhamentos indicados, uma vez que o serviço não exige qualquer retorno sobre a orientação e não pode garantir seu sucesso, principalmente quando feito para fora da cidade de São Paulo.

Atualmente, observa-se um grande aumento na procura por esse serviço. Isso exigiu da equipe uma reflexão sobre as possíveis variáveis envolvidas nesse fenômeno e uma revisão sobre o perfil dos usuários. Para fins deste artigo, foi feito um breve levantamento sobre as mensagens recebidas pelo núcleo.

\section{Dados sobre o serviço de orientação psicológica via e-mail do NPPI nos anos 2003 e 2004}

De 1995 (criação do núcleo) até 1999, foram recebidos poucos e-mails pedindo orientação psicológica, uma quantidade considerada inexpressiva, que girava em torno de um ou dois por ano. No ano 2000, foram recebidos catorze e-mails relativos à orientação psicológica; em 2001, esse número cresceu para oitenta e nove; no ano seguinte, atingiu a marca de duzentos e dezesseis; em 2003, duzentos e trinta e sete e-mails, e, por fim, no ano 2004, quatrocentas e uma mensagens dessa categoria foram recebidas. 


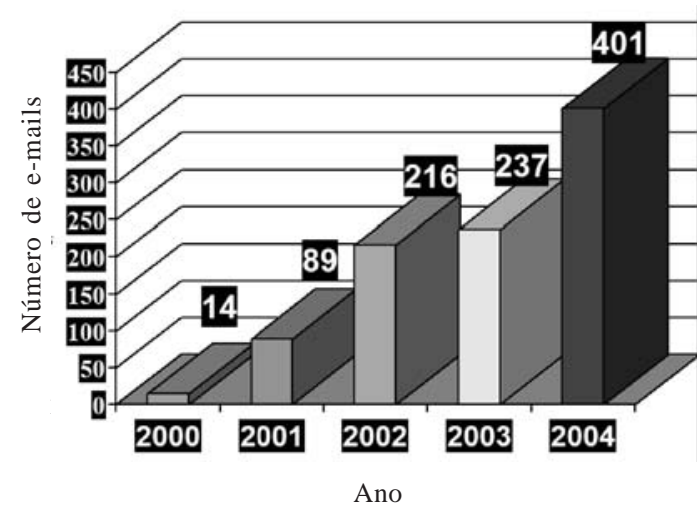

Figura 1: Número de e-mails de orientação recebidos pelo NPPI 2000 - 2004.

A fim de facilitar os registros do atendimento realizado, o total de e-mails recebidos passou a ser agrupado em número de "casos”. Muitas vezes, um usuário trocava mais de uma mensagem com o núcleo, a fim de esclarecer dados necessários à elaboração da melhor indicação para a pessoa. Assim, um "caso" se configura por um pedido de orientação de um determinado usuário, independentemente do número de trocas de e-mails. Assim, o mesmo "caso" de orientação (um mesmo usuário) pode chegar a ter até cinco trocas de e-mails. Essa troca limitada de mensagens é um dos pontos que distingue o serviço de orientação psicológica de um serviço de terapia on line. Na grande maioria dos casos, apenas uma troca de e-mail é realizada. Quando necessário, outras trocas são efetuadas, até que o encaminhamento para um serviço presencial seja realizado.

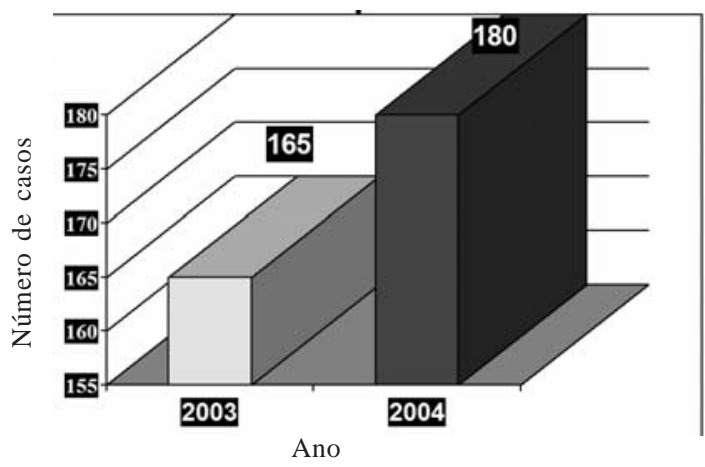

Figura 2: Número de casos de orientação em 2003 e 2004.
Para entender o grande aumento na procura do serviço de orientação psicológica por e-mail, primeiramente foi investigado o perfil do usuário desse serviço. Desse modo, tais dados podem indicar quem é esse indivíduo e porque utiliza esse meio específico. Realizada essa tarefa, é possível elaborar hipóteses acerca do aumento na procura do serviço, e, em conseqüência, aprimorar o serviço realizado pelo núcleo.

Inicialmente, cabe explicitar que todos os dados coletados foram obtidos de maneira espontânea, ou seja, dentro do serviço de orientação psicológica do NPPI, não há qualquer exigência por dados pessoais dos remetentes, e apenas foram analisados aqueles informados voluntariamente pelo usuário. Para o levantamento dos dados, foram computadas, no período de $1^{\circ}$ de janeiro de 2003 até 31 de dezembro de 2004, as informações sobre idade e sexo dos remetentes, o tema central das mensagens e o número de troca de $e$ mails. Além desses dados, como muitas mensagens de orientação contêm pedidos que não são necessariamente dirigidos aos remetentes, mas sim, para terceiros, tais como parentes, amigos e vizinhos, esse informe passou também a ser contabilizado (se os usuários pedem informações para si ou para outras pessoas).

No ano 2003, o NPPI respondeu duzentos e trinta e sete $e$-mails de orientação psicológica, que totalizavam cento e sessenta e cinco casos de orientação. Em 77\% dos casos, apenas uma troca de e-mail foi realizada com o interlocutor; 18\% foram constituídos de duas trocas, $4 \%$ de três, e apenas em $1 \%$ dos casos foram trocados quatro e-mails. Em 2003, os remetentes que informaram seus dados eram $57 \%$ de mulheres e $43 \%$ de homens. Quanto à idade, 52\% dos usuários informaram que tinham entre dezoito e vinte e sete anos. Dos pedidos feitos, $87 \%$ foram considerados pedidos de ajuda para o próprio remetente, e $13 \%$ relatavam problemas vividos por terceiros. 
No ano 2004, o número de e-mails de orientação saltou para quatrocentos e um, sendo atendidos cento e oitenta casos. No mesmo ano, $86 \%$ dos casos se constituíram de apenas uma troca de e-mail, sendo que $13 \%$ tiveram duas trocas e apenas $1 \%$ contou com cinco trocas de mensagens. Ainda em 2004, os remetentes eram $66 \%$ de mulheres e $34 \%$ de homens. A idade informada se concentrou na faixa de vinte e três a trinta e dois anos, contabilizando $40 \%$ do total informado, e, do número absoluto de casos, 86\% procuraram orientação para si e 14\%, para outras pessoas.

Os e-mails recebidos pelo NPPI apresentam uma grande diversidade de assuntos. Geralmente, as mensagens envolvem relatos detalhados de vivências, situações e experiências próprias, em sua maioria dolorosas e conflituosas. Os temas mais recorrentes nesse tipo de mensagem envolvem relatos de baixa auto-estima, descontentamento quanto à qualidade de vida, tristeza excessiva, insatisfação com a própria vida e descrição de sintomas. Outros temas muito presentes giram em torno da sexualidade, em especial a dúvidas em relação à orientação sexual e experiências homossexuais, bem como os medos e anseios relativos à afirmação dessa orientação sexual diante da sociedade.

A Clínica da PUC-SP dispõe de um núcleo de atendimento às pessoas enlutadas, o Laboratório de Estudos sobre o Luto (LELu). Por esse motivo, são freqüentes também os $e$-mails que tratam da questão da morte de pessoas queridas, como a perda de familiares ou de amigos. Essas mensagens são respondidas em primeira instância, e depois são encaminhadas para o referido laboratório. Outro tema freqüente nos pedidos recebidos por e-mail envolve relacionamentos afetivos e sexuais. São narrativas detalhadas de problemas relativos ao relacionamento de casais, de qualquer orientação sexual, como conflitos presentes em namoros, casamentos, ou ainda questões envolvidas ao "ficar", separação, traição e divórcio. Também constam na lista dos temas mais freqüentes as questões de relacionamento sexual insatisfatório e dificuldades nas relações sexuais em geral, tais como impotência, parafilias, etc.

A família e seus desdobramentos são tópicos bastante recorrentes, com relatos sobre problemas, conflitos e intrigas no âmbito familiar. Também existem pedidos que envolvem conselhos sobre como lidar com o comportamento infantil, crises de adolescência, com patologias típicas da infância e juventude e questões escolares como notas baixas, indisciplina e dificuldade das crianças em acompanhar as aulas.

Existem também outros temas recorrentes que atravessam a área da Psicologia e envolvem outras áreas ou especialidades, tais como a Medicina, a fonoaudiologia, a fisioterapia e a Pedagogia. São freqüentes os relatos sobre transtornos neurológicos, somáticos e a descrição de sintomas físicos e/ou psíquicos. Muitas dessas queixas se referem a transtornos alimentares, depressão, esquizofrenia, transtorno bipolar, transtorno obsessivocompulsivo, transtorno de pânico, tentativas de suicídio e ainda queixas relacionadas à dependência de álcool e drogas.

Ainda por causa da especificidade do núcleo, recebem-se muitos e-mails cujo tema central se acha ligado a questões relacionadas à informática e à internet. São tópicos que envolvem, de maneira geral, o modo como as pessoas têm usado as diferentes possibilidades da rede e dos artefatos eletrônicos e como os relacionamentos se estabelecem através desses meios, sendo comuns as queixas referentes ao uso patológico da internet, vícios em jogos eletrônicos, encontros marcados através da internet e namoro, sexo e traição virtual. 


\section{Resultados}

Como citado anteriormente, o serviço se iniciou de maneira espontânea. Nesse contexto, assim que o núcleo recebeu os primeiros e-mails, o questionamento central levantado pela equipe foi: "Porque alguém enviaria um pedido de orientação psicológica por e-mail?” Diante disso, foram levantadas algumas primeiras hipóteses (Farah, 2004b), que serão retomadas brevemente.

Em primeiro lugar, a questão do "anonimato" propiciado pela internet pareceu ser um motivo forte pelo qual as pessoas se utilizavam desse meio para expor suas questões psicológicas. Os indivíduos se sentem protegidos pelo anonimato, uma vez que podem nos enviar suas questões sem a necessidade de se exporem, seja a partir de seu real endereço de correspondência eletrônica ou de um temporário, que facilmente pode ser criado apenas para essa finalidade. A ausência de um interlocutor fisicamente presente também parece permitir que sejam abordados tópicos delicados, tais como relatos sobre experiências sexuais e condutas socialmente reprováveis, de uma maneira mais direta, sem a censura oriunda da identificação.

Outra hipótese levantada foi sobre a "catarse terapêutica através da máquina”, ou seja, o sujeito usaria o e-mail para descarregar suas emoções, realizando, de certa forma, uma purgação frente ao computador. Assim, com um interlocutor que não julga - a máquina muitas emoções e sentimentos podem ser escritos, lidos e relidos antes de serem enviados. Desse modo, o sujeito que escreve pode, por vezes, estabelecer, na linguagem ou na palavra, um substituto para o ato (Laplanche e Pontalis, 1967), evocando, revivendo e descarregando os acontecimentos e afetos relacionados sob a forma de relatos via e-mail.

Pelo próprio conteúdo dos e-mails, é possível notar que muitos indivíduos procuram, no serviço de orientação psicológica, uma solução pronta, como se pudesse ser enviada uma espécie de receita a ser seguida para resolução de seus problemas, resposta essa que não demandaria nem muito esforço e nem muito tempo. A questão da velocidade propiciada pelo e-mail - em pouco tempo a mensagem é escrita, enviada e recebida - mobiliza a expectativa de que o sujeito vá ser atendido e de que seu problema também seja solucionado com a mesma rapidez. Seria a busca de uma solução mágica e rápida para o problema, em contraste com os atendimentos psicológicos convencionais. Assim, por e-mail, supostamente não haveria a necessidade de se submeter a um certo tipo de tratamento, que eventualmente pode ser longo e demorado.

De certa forma, é possível ainda que, para o remetente, o fato de um profissional ler o que ele escreveu sobre si ou sobre os outros já se configure como um tipo de contato com alguém que esteja disposto a "escutá-lo", mesmo que posteriormente ele não volte a escrever. Essa hipótese, aliás, tem sido reforçada por mensagens cujo conteúdo possui um teor de "depoimento", no qual a pessoa não apresenta propriamente um pedido de ajuda, mas apenas relata uma vivência, um questionamento ou sentimento que - segundo a expectativa expressa - "possa ser lido por alguém”, como muitos usuários relatam.

Diante do expressivo aumento do número de casos nos anos 2003 e 2004, novas hipóteses acerca do motivo pelo qual os indivíduos procuram o serviço de orientação psicológica via e-mail foram levantadas. A relevância dessas informações está pautada na busca pelo acompanhamento da evolução desse fenômeno que se multiplica a cada ano. Encarando esse cenário, novas reflexões produziram novas hipóteses, não só buscando a compreensão do contínuo crescimento dessa demanda, mas também na tentativa de se
Outra hipótese levantada foi sobre a "catarse terapêutica através da máquina", ou seja, o sujeito usaria o email para descarregar suas emoções, realizando, de certa forma, uma purgação frente ao computador. Assim, com um interlocutor que não julga - a máquina - muitas emoções e sentimentos podem ser escritos, lidos e relidos antes de serem enviados. 
conhecer cada vez mais quem é o sujeito que o usa, como também - e essencialmente buscando aprimorar a forma de prestação desse serviço.

Uma das novas hipóteses para o crescimento do número de e-mails de orientação é a “popularização do acesso e uso da internet” e do computador nos últimos anos. Entre os fatores que viabilizaram essa expansão, destaca-se o aparecimento da internet gratuita, que permitiu que muitos usuários pudessem se conectar sem despesas com provedores. Outro evento que contribuiu para esse crescimento foi a expansão de estabelecimentos que permitem e facilitam o acesso à internet, tais como lan houses, cybercafés e centros de ensino onde o uso é gratuito (escolas, universidades, bibliotecas, centros de estudo, escola de línguas, etc.).

A popularização da internet também se deve à queda dos preços e maior disponibilidade dos microcomputadores, que são atualmente comercializados até mesmo em lojas de eletrodomésticos. Diante desses acontecimentos, a facilidade do acesso permitiu que mais pessoas se utilizassem desse meio para pedir ou procurar ajuda para suas dificuldades.

Outro motivo que possivelmente elevou a procura pelo serviço é a “divulgação desse serviço na mídia”. Desde 2003, o NPPI tem mantido uma coluna em um portal de grande visibilidade na internet. Diversas vezes, os textos foram colocados em destaque na página principal desse site, divulgando aspectos conceituais do trabalho do núcleo. Durante o período de destaque do texto no portal, o número de e-mails recebidos aumenta significativamente, pois existe um link vinculando essa coluna ao serviço de orientação por e-mail.

A exposição na mídia impressa também contribui para esse aumento. Não é raro que uma reportagem em jornais ou revistas de grande circulação bem como programas televisivos elevem consideravelmente a procura pelo serviço. Nos meios de comunicação atuais, é cada vez mais comum a indicação de endereços eletrônicos para maiores informações ou contatos eventuais.

O núcleo observa, em muitos pedidos de orientação, a "ressalva sobre os limites de ordem financeira”. Muitos usuários contam que estão procurando o serviço de orientação porque não podem pagar por um serviço de psicoterapia. Muitos pedem indicação de onde podem ser atendidos presencialmente de forma gratuita ou a baixo custo.

Alguns usuários confundem, inicialmente, o serviço de orientação com a psicoterapia on line, acreditando que se trata de um serviço psicoterapêutico gratuito. O NPPI oferece orientação gratuitamente e está disponível na internet para todos os usuários de língua portuguesa, contudo, em conformidade com as já citadas Resoluções do Conselho Federal de Psicologia, não presta o serviço de psicoterapia on line.

Existem e-mails que descrevem, com detalhes, bens e posses dos remetentes, possibilitando a observação clara de diferentes condições financeiras dos usuários. Pela freqüência da citação da ressalva financeira, juntamente às informações prestadas pelos usuários sobre seus recursos econômicos, é possível questionar o nível de prioridade atribuído a um processo psicoterapêutico, uma vez que alguns usuários afirmam possuir condições financeiras que seriam suficientes para arcar com as despesas de um atendimento presencial. É possível que muitos usuários disponham de condições financeiras, mas não estão dispostos a investir numa psicoterapia presencial, e, por isso, procuram o serviço com a intenção de fazê-la gratuitamente e/ou como uma solução “meio termo”, isto é, um atendimento gratuito, mas livre, concomitantemente, de maiores responsabilidades e vínculos. Vale destacar que 
essa postura se relaciona fortemente com a hipótese já apontada de que, por vezes, o serviço de orientação psicológica via $e$-mail possa ser idealizado como uma resposta "mágica” aos problemas enfrentados pelos remetentes. Cabe lembrar que não é exclusivo de uma abordagem on line o fato de que o contrato financeiro entre psicólogo e usuário/ paciente envolva muitas outras questões, além de apenas o pagamento pelo serviço prestado.

Um ponto digno de nota é o fato de que a internet tende a criar uma cultura de serviços gratuitos. Atualmente, informações, músicas, filmes, livros, fotos, cursos e muitos serviços estão acessíveis pela rede mundial de computadores livres de encargos. Dessa forma, muitos supõem que os serviços oferecidos pelos psicólogos na internet são exatamente os mesmos que os exercidos presencialmente, com a vantagem de serem desprovidos de cobrança ou custo.

Uma outra tendência que a internet tende a reforçar é o que se poderia chamar de "cultura do menor esforço”, ou seja, a busca pelo caminho aparentemente mais rápido e confortável de se obter solução para seus problemas. Hoje, com boa parte do cotidiano informatizado, o computador e a internet passaram a fazer parte da cultura e a ocupar grande parte da vida de muitos. O e-mail, nesse contexto, configura-se como uma facilidade, permitindo, a essas pessoas, o surgimento da suposição de que, para buscar ajuda, não é mais necessário sair de casa, ou mesmo telefonar.

Buscar um psicólogo presencialmente implica uma série de regras e comprometimentos: encontrar um profissional, ligar para ele, marcar uma entrevista, ir até o local, conhecêlo e contar seus problemas. Por e-mail, nada disso é necessário. Simbolicamente - ou supostamente -, o psicólogo já está ali, ouvindo, sempre disponível. Uma mensagem por correio eletrônico pode ser mandada a qualquer hora, inclusive durante a madrugada, horário pouco comum nos consultórios e outras instituições. Também não há trânsito, gastos com transporte, condições climáticas desfavoráveis, horários ou regras. O usuário expressa o que deseja, quando, onde, o quanto e como quiser, não havendo certos limites como os que geralmente se encontram no atendimento presencial. Esse cenário remete à facilidade do e-mail: não é preciso muito esforço, pois o profissional está a um teclado de distância.

A “busca por uma ajuda em língua própria” é uma das grandes possibilidades abertas pela comunicação mediada pelo computador. Freqüentemente, recebem-se e-mails de brasileiros residentes em outros países, especialmente do Japão, dos Estados Unidos e de alguns países da Europa, e o número de e-mails provenientes de brasileiros residentes nesses países tem aumentado nos últimos anos.

A ajuda psicológica é um tipo de serviço que passa essencialmente pela linguagem e pelos padrões históricos, sociais e culturais de cada comunidade. Muitos brasileiros residentes no exterior relatam a dificuldade em expressarse em outra língua, o que acaba atrapalhando ou até mesmo inviabilizando a procura por ajuda no local de residência. Há também relatos sobre os sentimentos daqueles que habitam um local com grande diferença cultural, onde aparecem temas como a solidão, a questão do preconceito e as diferenças religiosas, para citar alguns poucos. O serviço de orientação psicológica via $e$-mail se configura, portanto, como uma possibilidade de a pessoa ser ouvida e entendida por aqueles que compartilham da mesma língua e cultura. É interessante destacar, a título de curiosidade, que, algumas vezes, também aparecem pedidos de usuários natos e residentes de outros países, que vivem imersos em diferentes contextos mas que partilham da mesma língua ou de língua semelhante, especialmente indivíduos de Portugal e alguns 
países da África, como Moçambique, por exemplo. O teor de suas mensagens é semelhante ao dos brasileiros, mas suas particularidades são visíveis tanto pela grafia, concordância e linguajar, como pelos endereços de e-mail. Também recebemos mensagens de outros países da América Latina, escritos em espanhol.

\section{Considerações finais}

As rápidas transformações causadas pelas freqüentes atualizações no cenário tecnológico requerem constantes reflexões para acompanhar as mudanças contemporâneas. A análise dos dados aqui apresentados, referentes aos anos 2003 e 2004, teve, como intuito, a reflexão e a compreensão do constante aumento na procura pelo serviço de orientação psicológica via e-mail, a partir do conteúdo de suas mensagens, desvendando quem é esse usuário, para quem ele escreve, porque utiliza esse serviço, e, em conseqüência, desenvolver uma forma melhor de atendê-lo.

As considerações hipotéticas levantadas a partir da análise dos dados dos e-mails de orientação psicológica dos anos 2003 e 2004 (a popularização do acesso à internet e do serviço via mídia, a questão financeira, a cultura de serviços gratuitos e do menor esforço e a busca por ajuda em língua própria ou no país de origem) vêm somar-se às outras anteriormente consideradas (a questão do anonimato, da catarse terapêutica através da máquina, da velocidade propiciada pela internet e a busca pela resposta mágica). Nesse sentido, é possível que essas teorias se manifestem simultaneamente, pois estão ligadas umas às outras e formam grandes intersecções, tornando-se complementares.

Levantar novas considerações acerca do serviço de orientação psicológica por e-mail é refletir, atravessando o próprio serviço, sobre as transformações pertinentes ao presente e as transformações providas pelas mudanças tecnológicas. É digno de nota afirmar que, diante desse constante movimento das transformações atuais, não é a intenção deste artigo, nem seria possível, encerrar essa questão.

Atualmente, o uso do computador e da internet tem se tornado cada vez mais popular. $\mathrm{O}$ número crescente de usuários torna o serviço de orientação psicológica por e-mail uma via de fácil acesso. Entretanto, esse fenômeno parece estar relacionado não apenas ao aumento do acesso, mas também à incorporação das novas tecnologias como uma ferramenta para a expressão humana (Novo, 2004). Em outras palavras, o aumento da demanda do serviço também é reflexo da transformação da comunicação humana operada pelo computador, pela internet e por outros recursos da informática. Esses recursos aparecem como o novo meio através do qual o ser humano interage, podendo expressar-se e pedir auxílio por essa via.

Cabe ressaltar que as interações humanas não passam incólumes frente às atualizações dos recursos de comunicação. A internet torna mais complexas as relações humanas, abrindo novas possibilidades, mas não necessariamente substituindo outras formas de interação, como, por exemplo, o contato presencial e pelo telefone.

Diante disso, o serviço de orientação psicológica por e-mail é apenas mais um dos recursos pelo qual se pode pedir e obter ajuda; não pretende substituir nenhum serviço psicológico presencial. Pelo contrário, muitas vezes se propõe a facilitar a procura e a chegada a um serviço presencial mais adequado e eficiente. Nesse sentido, propõese a iniciar, com o interlocutor, uma reflexão que possibilite transformar sua "queixa inicial" em uma demanda para atendimento presencial, capaz de propiciar uma busca apropriada para a solução de suas questões. 
Não parece haver um perfil exclusivo para os usuários desse serviço. Em sua maioria, são homens e mulheres, na faixa de idade entre dezoito e trinta e dois anos, que utilizam a internet como mais um recurso para procurar orientação para seus problemas pessoais. Todavia, atenta às possibilidades abertas nesse campo, a Psicologia pode utilizar-se desse recurso como aliado à prática psicológica convencional. Do mesmo modo que a internet pode acelerar a democratização e o acesso à informação pelo processo de inclusão digital, ela também pode tornar a Psicologia mais acessível a parcelas da população antes não contempladas ou que só tomaram contato com os serviços psicológicos através da rede. Enfim, a constante reflexão e pesquisa realizadas pelo Núcleo pode fornecer informações relevantes para nortear o crescimento dessa modalidade de serviço psicológico, que já se constitui em uma área em desenvolvimento, visto o crescente número de seus usuários ano a ano. Nesse sentido, as reflexões apresentadas são, essencialmente, contribuições para elaborar e estruturar um trabalho preocupado com a qualidade e pautado em princípios éticos, em resposta a um serviço criado a partir de uma demanda social espontânea.

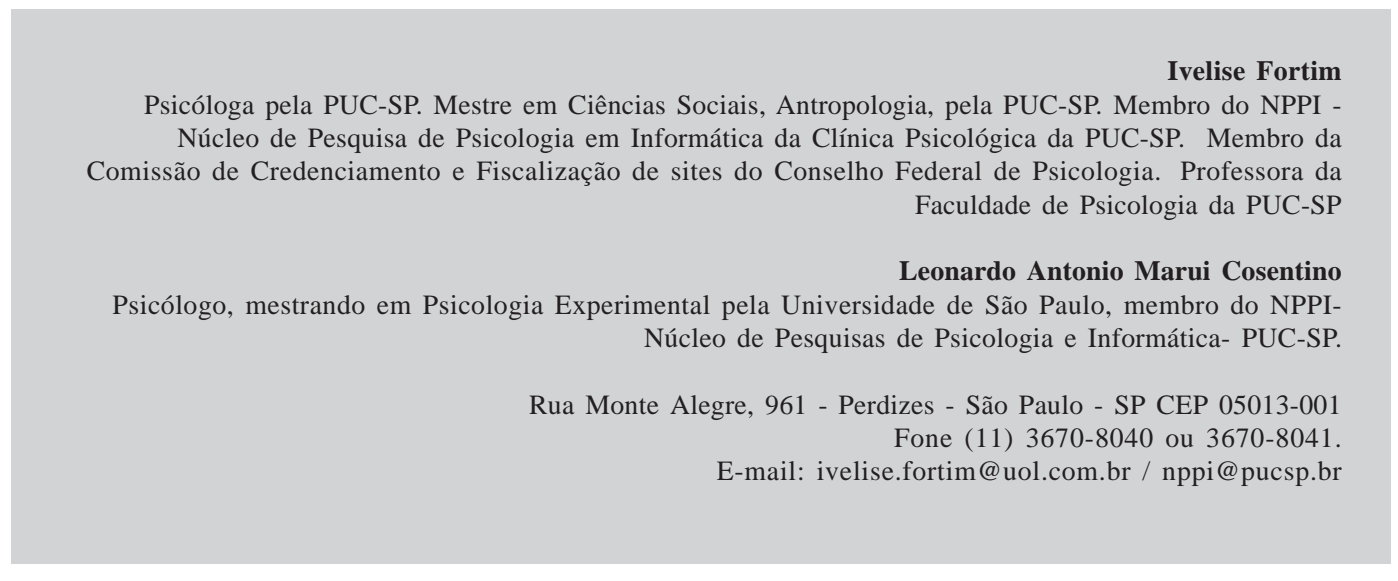

Recebido 02/12/05 Reformulado 14/08/06 Aprovado 22/12/06

CÓDIGO DE ÉTICA DO PSICÓLOGO - Disponível em http:// w w w. crps p.org.br/a_ori e n/ codigo/ fr_codigo_etica_indice_new.htm Acessado em (27/09/2005).

NOVO, L. C. Considerações acerca da Informática na Atitude Humana: o Computador e a internet como Ferramentas do Ser Humano. In: R. M. Farah (org.) Psicologia e Informática: o Ser Humano diante das Novas Tecnologias. São Paulo: Oficina do Livro, 2004.

FARAH, R. M. NPPI- Núcleo de Pesquisas em Psicologia e Informática: Serviço de Informática da Clínica-Escola Ana Maria Poppovic. In: R. M. Farah (org.) Psicologia e Informática: o Ser Humano diante das Novas Tecnologias. São Paulo: Oficina do Livro, 2004a, pp.19-23.

Orientação Psicológica via e-mail: Serviço Oferecido pela Clínica Psicológica da PUC-SP. In: R. M. Farah (org.) Psicologia e Informática: o Ser Humano diante das Novas Tecnologias. São Paulo: Oficina do Livro, 2004b, pp.19-23.
FORTIM, I. Terapia on line e Orientação Psicológica:Diferenças. In: R. M. Farah (org.) Psicologia e Informática: o Ser Humano diante das Novas Tecnologias. São Paulo: Oficina do Livro, 2004.

LAPLANCHE, J.; PONTALIS, J. B. Vocabulário da Psicanálise. $5^{\mathrm{a}}$ ed. Lisboa - Portugal: Moraes, 1967-1979.

RESOLUÇÃO nº 012/2005 - Regulamenta o atendimento psicoterapêutico e outros serviços psicológicos mediados por computador e revoga a Resolução CFP n ${ }^{\circ}$ 003/2000. Disponível em: http://www.pol.org.br/legislacao/pdf/resolucao2005-12.pdf. Acessado em (27/09/2005).

Referências 